$\sqrt{3}$

J. bio-sci. 15: 111-116, 2007

ISSN 1023-8654

http://www.banglajol.info/index.php/JBS/index

\title{
PHOTOAUTOTROPHIC AND PHOTOMIXOTROPHIC MICROPROPAGATION OF THREE POTATO CULTIVARS
}

\author{
M H Rahman? and A A Alsadon \\ Department of Plant Production, College of Food and Agricultural Sciences, \\ King Saud University P O Box 2460, Riyadh 11451, Saudi Arabia
}

\begin{abstract}
The present study was aimed to compare the photoautotrophic (PAM) and photomixotrophic micropropagation (PMM) of three potato cultivars (Hermes, Rosetta and Asterix). Cultures were initiated from single node explants and established in MS basal medium with some modifications. Potato plantlets responded in sugar-free media although sugar-containing media (PMM1 and PMM2) performed better as compared to that of sugar-free (PAM1 and PAM2) media. The PMM1 produced shoot length averaging $6.25 \mathrm{~cm}$ with 8.08 nodes and weighing $0.24 \mathrm{~g}$ fresh weight of plantlet. On the other hand, PAM1 grown culture produced $4.03 \mathrm{~cm}$ shoot length, 8 nodes and $0.06 \mathrm{~g}$ of fresh weight. Shoot length and fresh weight of plantlets were significantly higher in PMM1 and PMM2 based media. Whereas the number of nodes per shoot was not significantly different on media with or without sugar (except the media PAM2). Sugar and vitamin-free media ( PAM2 ) performed inferior in all the traits.
\end{abstract}

Key words: Potato, Photoautotrophic and Photomixotrophic Micropropagation.

\section{Introduction}

Propagation of plants through tissue culture is heterotrophic in nature. Tissue culture systems have relied on the use of exogenous sugar as a source of carbon for growth. However, new culture protocols and innovative design of growth containers providing aeration high $\mathrm{CO}_{2}$ in the culture vessel and high light intensity make it possible for the adaptation of photoautotrophic culture systems. In addition, new culture protocols allow plantlets to be successfully cultured in vitro (Desjardins 1995). Poor gas permeability due to culture vessel closure gradually decreases $\mathrm{CO}_{2}$ concentrations thus explaining the low photosynthesis in vitro (Falque et al. 1991). Over the past few decades' attempts have been made to develop photoautotrophic culture (no sugar media) by adopting external $\mathrm{CO}_{2}$ or forced ventilation to the culture vessel. Newly developed photoautotrophic micropropagation systems (PAM) were adapted to produce quality plant propagules at minimum usage of resources, to maximize production and minimize cost. It was observed that plants can grow vigorously in the absence of sugar if provided with proper ventilation system coupled wih high photosynthetic photon flux (PPF) of $100-150 \mu \mathrm{mol} \mathrm{m}-2 \mathrm{~s}-1$ and lower percentage of relative humidity inside the culture vessel (Chun and Kozai 2001).

Photoautotrophic micropropagation system that uses a sugar-free culture medium has many advantages over the conventional photomixotrophic micropropagation system (PMM) that uses a sugar containing medium (Kozai 1991). The advantages include minimum risk of contamination in the culture media, enhancement of plantlet growth at a high photosynthetic photon flux (PPF) and a high $\mathrm{CO}_{2}$ concentration inside the vessel (Fujiwara et al. 1988, Kozai and Iwanami 1988). To increase $\mathrm{CO}_{2}$ concentration in the vessel under aseptic conditions, both natural and forced ventilation methods have been employed (Xiao and

\footnotetext{
? Author for correspondence. Email .mhrahmanbd01@hotmail.com.
} 
Kozai 2004). Kubota and Kozai (1992) successfully developed the photoautotrophic growth of potato plantlets with forced ventilation. Further, photoautotrophically produced propagules do not require acclimatization prior to transplanting in the ex-vitro conditions (Kozai et al. 1987, Fujiwara et al. 1995). This system can be used for different horticultural and woody plant species with minimum modification (Chun and Kozai 2001).

The present study was aimed to investigate the in vitro response of three potato cultivars in sugar free media as compared to the traditional sugar containing MS media.

\section{Materials and Methods}

Three potato cultivars (Hermes, Rosetta and Asterix) were selected to conduct the present investigation. The study was carried out at Plant Tissue Culture Laboratory, in the Department of Plant Production, College of Food and Agricultural Sciences at King Saud University, Saudi Arabia.

The in vitro grown plantlets were separated into single nodes (each with one leaf and $0.5 \mathrm{~cm}$ in length) and cultured in MS (Murashige and Skoog 1962) basal media. The media used for the present study are mentioned in Table 1.

Table 1. Media components for photoautotrophic and photomixotrophic micropropagation.

\begin{tabular}{|c|c|}
\hline Media & Components \\
\hline PMM1 & MS media with sugar $(30 \mathrm{~g} / \mathrm{l})$ and vitamins \\
\hline PAM1 & MS media without sugar and with vitamins \\
\hline PMM2 & MS media with sugar $(30 \mathrm{~g} / \mathrm{l})$ but vitamin-free \\
\hline PAM2 & MS media without sugar and vitamins \\
\hline
\end{tabular}

All the media were free from growth regulators and the $\mathrm{pH}$ was adjusted to $5.7 \pm 0.1$ prior to adding $7 \mathrm{~g} / \mathrm{l}$ agar (Difco-Bacto). All media were sterilized by autoclaving at $121^{\circ} \mathrm{C}$ for 20 minutes at $1 \mathrm{~kg} \mathrm{~cm} 2$ pressure. Explants were cultured in test tubes $(25 \times 150 \mathrm{~mm})$ containing $10 \mathrm{ml}$ media fitted with cotton plugs. Culture tubes were arranged in a slant condition in culture rack so that they were exposed to uniform light environment.

To examine the effect of air ventilation, test tube plugs were opened twice a week in front of running laminar air flow for few minutes and closed again. Photoperiod was maintained at 14/10 hours light /dark regime with a PPF of $15 \mu \mathrm{mol} \mathrm{m} \mathrm{-2} \mathrm{s-1} \mathrm{and} \mathrm{the} \mathrm{temperature} \mathrm{was} \mathrm{maintained} \mathrm{at} 25 \pm 1^{\circ} \mathrm{C}$. The study was designed with completely randomized block design. It consisted of four treatments with three replications each. Each replication consisted of four cultures. The following growth traits were evaluated after 21 days of culture : a) shoot length b) number of nodes per shoot and c) fresh weight of plantlets .Data were analyzed using standard statistical method and mean separation was carried out by Duncan's Multiple range test and the analysis of variance were summarized in terms of $F$ values (Table 2). 


\section{Results and Discussion}

The analysis of variance indicated significant $(p<0.05$ and 0.01 ) differences among cultivars and treatments (Table 2). The interaction effects were also significant for all traits except the node number per shoot. These results indicated that sugar had a key role on shoot length and fresh weight of plantlets.

Table 2. Analysis of variance for shoot length, number of nodes and fresh weight of plantlets of three potato cultivars.

\begin{tabular}{|c|c|c|c|c|}
\hline \multirow{2}{*}{ Source of variation } & df & $\begin{array}{c}\text { Shoot length } \\
(\mathrm{cm})\end{array}$ & $\begin{array}{c}\text { Number of nodes / } \\
\text { shoot }\end{array}$ & $\begin{array}{c}\text { Fresh weight of } \\
\text { plantlets }(\mathrm{g})\end{array}$ \\
\hline Cultivar (C) & 2 & $112.16^{\star}$ & $29.35^{\star}$ & $10.95^{\star}$ \\
\hline Treatment (T) & 3 & $25.06^{\star}$ & $5.05^{\star}$ & $98.56^{\star}$ \\
\hline $\mathrm{C} \times \mathrm{T}$ & 6 & $7.49^{\star}$ & $0.56 \mathrm{~ns}$ & $6.00^{\star}$ \\
\hline Error & 22 & & & \\
\hline
\end{tabular}

*, Significant at $5 \%$ and $1 \%$ level respectively; ns- non-significant

Single nodal cuttings commenced their growth within 2-3 days after culture into the media. Shoot length was significantly different between sugar-free (PAM1 and PAM2) and sugar based (PMM1 and PMM2) media but the number of nodes per shoot was not significant at both treatments except PAM2 (data not shown). Among the three cultivars, Hermes had the highest shoot length $(6.25 \mathrm{~cm})$ in PMM1 followed by PMM2 $(6.03 \mathrm{~cm})$ while the Asterix had the lowest $(2.22 \mathrm{~cm})$ in PAM1 (Fig. 1). Rosetta gave moderate performance. The PAM2 media had resulted in poor response. The highest numbers of nodes (8.66) was obtained in Hermes on PMM2 media and the lowest number was recorded in Asterix (5.91) on PAM2. Node numbers of Hermes plantlets were significantly higher than in Rosetta and Asterix (Fig. 2).

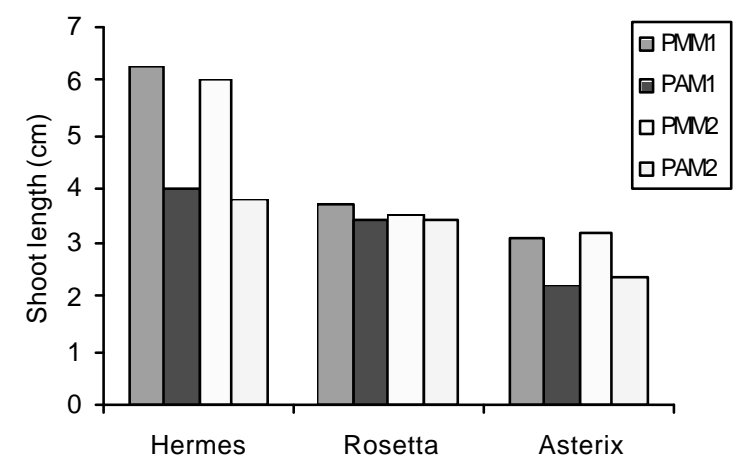

Fig. 1. Shoot length of three potato cultivars on different media treatments. 


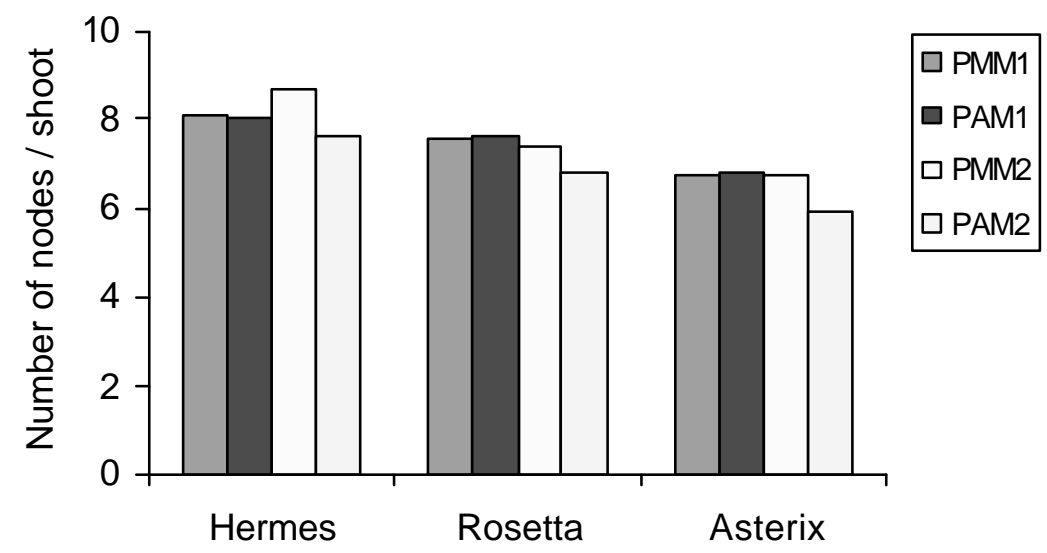

Fig. 2. Number of nodes / shoot of three potato cultivars on different media treatments.

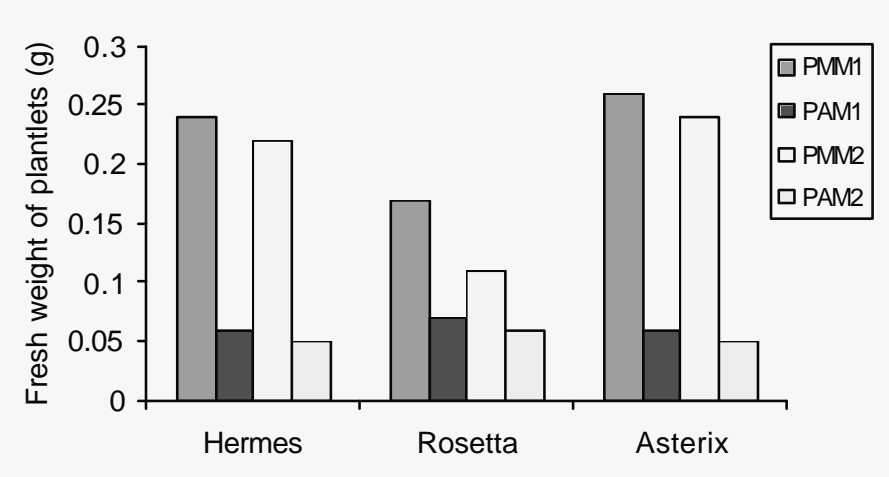

Fig. 3. Fresh weight of plantlets of three potato cultivars on different media treatments.

Fresh weight of plantlets was found significantly higher in sugar containing (PMM1 and PMM2) than sugarfree (PAM1 and PAM2) media. The highest fresh weight $(0.26 \mathrm{gm})$ was achieved in Asterix at PMM1 (Fig. 3). Among the cultivars studied Hermes was the superior for all the traits.

PMM1 media performed significantly better in all the parameters except node number per shoot. The results also indicated that sugar and vitamin in the media does not influence the number of nodes. In this case, sugar free (except PAM2) and sugar containing (PMM1 and PMM2) media showed no significant difference. On the other hand both sugar containing media always showed higher fresh weight of plantlet than sugar-free media. This result is in agreement with Kozai et al. (2002). No significant differences were found between the PAM1 and PAM2 for fresh weight but the significant differences were found between PMM1 and PMM2. The plantlets were normal in all the treatments except in PAM2 which had light green colour appearance. 
Recent studies (Jeong et al. 1995, Kozai et al. 1999, Nguyen and Kozai 1998) revealed that most chlorophyllous plants in vitro have the ability to grow photoautotrophically but the low concentration of $\mathrm{CO}_{2}$ in the air tight culture vessel during the photoperiod is the main cause of low photosynthetic rate of plants. Photoautotrophic growth of in vitro plantlets can be significantly promoted by increasing $\mathrm{CO}_{2}$ concentrations and light intensity or photon flux (PPF) by decreasing the relative humidity in the culture vessel. When culture vessel with a high ventilation or a high rate of air exchange is used, the relative humidity in the vessel is reduced which in turn increase the transpiration rate (Chun and Kozai 2001).

It is reported that photoautotrophic micropropagation by supplying air with $\mathrm{CO}_{2}$ have been successfully used on Russet Burbank potato and that has been recommended to seed potato production (Pruski et al. 2002). Plantlets produced photoautotrophically on media with no sucrose were very similar to those produced traditionally (Pruski et al. 2002). We noticed that if the culture vessel was exposed for few minutes (2/3) in front of running laminar air flow and followed by re-closing, plantlets showed better growth (data not shown). This practice may allow for better air flushing or ventilation occurs inside the culture vessel and improved growth of in vitro plantlets. Hayashi et al. (1995) reported that the number of air exchange and lighting cycle are important for the photoautotrophic growth of plantlets. Air-tight culture vessel showed lower performance than those of cotton plug capping vessels due to lack of proper ventilation. Extreme fluctuations of $\mathrm{CO}_{2}$ concentrations between duration of light and darkness cycles can occur in air tight vessel but those with natural ventilation or with forced ventilation such fluctuation is very small (Zobayed et al. 1999). The low rate of photosynthesis under airtight vessel was probably due to the prolonged exposure of plantlets to low $\mathrm{CO}_{2}$ and high ethylene concentration which can reduce the photosynthetic ability of the leaves.

It is hoped that photoautotrophic micropropagation technique by using proper ventilation system and coupled with high light intensity could be efficient tools over the photomixotrophic micropropagation system. Future studies are needed to explore this novel technique. The technique may be economically feasible for the large scale potato production.

\section{References}

Chun C and Kozai T (2001) A closed transplant production system, a hybrid of scaled-up micropropagation system and plant factory. J. Plant Biotechnol. 3(2): 59-66.

Desjardins $Y$ (1995) Factors affecting $\mathrm{CO}_{2}$ fixation in striving to optimize photoautotrophy in micropropagated plantlets. Plant tiss. Cult. and biotechnol. 1: 13-25.

Falque M, Compan D and Galzy R (1991) A method for the study of $\mathrm{CO}_{2}$ exchange on in vitro cultured of Vitis rupestris plantlets. Plant Cell Tiss. Org Cult. 27: 175-181.

Fujiwara K, Kozai T and Watanabe I (1988) Development of a photoautotrophic tissue culture system for shoots and lor plantlets at rooting and acclimatization stages. Acta Hort. 230: 153-158.

Fujiwara K , Kira S and Kozai T (1995) Contribution of photosynthesis to dry weight increase of in vitro potato cultures under different $\mathrm{CO}_{2}$ concentrations. Acta Hort. 393: 119-126.

Hayashi M, Fujiwara K, Kozai T, Tateno M and Kitaya Y (1995) Effects of lighting cycle on daily $\mathrm{CO}_{2}$ exchange and dry weight increase of potato plantlets cultured in vitro photoautotrophically. Acta Hort. 393: 213-218. 
Jeong B R, Fujiwara K and Kozai T (1995) Environmental control and photoautotrophic micropropagation. Horticultural Reviews 17: $125-172$.

Kozai T (1991) Micropropagation under photoautotrophic conditions. In: Debergh P C, Zimmerman R H (Eds.) Micropropagation technology and application. Kluwer Academic Publishers, Dordrecht. pp. 447-469.

Kozai T, Kubota C, Zobayed S, Nguyen Q T, Afreen-Zobayed F, Heo J (1999) Developing a mass propagation system of woody plants. In: Watanabe K, Komamine A (Eds.), Challenge of plant and agricultural sciences Kluwer Academic Publishers, Dordrecht. pp. 293-307.

Kozai T and Iwanami Y (1988) Effects of $\mathrm{CO}_{2}$ enrichment and sucrose concentration under high photon fluxes on plantlet growth of Carnation Pianthus caryophyllus L) in tissue culture during the preparation stage. J. Japan. Soc. Hort. Sci. 57: 279-288.

Kozai T, Iwanami $Y$ and Fujiwara $\mathrm{K}$ (1987) Environment control for mass propagation of tissue cultured plantlets.(1) Effects of $\mathrm{CO}_{2}$ enrichment on the plantlet growth during the multiplication stage. Plant Tiss. Cult. Lett. 4: 22-26.

Kozai T, Koyama Y and Watanabe I (2002) Multiplication of potato plantlets in vitro with sugar-free medium under high photosynthetic photon flux. Acta. Hort. pp.230.

Kubota C and Kozai T (1992) Growth and net photosynthetic rate of Solanum tuberosum in vitro under forced and natural ventilation. Hort. Sci. 27: 1312-1314.

Murashige T and Skoog F (1962) A revised media for rapid growth and bioassys with tobacco tissue cultures. Physiol. Plant 15: 473-497.

Nguyen Q T and Kozai T (1998) Environmental effects on the growth of plantlets in micropropagtion. Environment control in biol. 36: $59-75$.

Pruski K, Astatkie T, Mirza M and Nowak J (2002) Photoautotrophic micropropagtion of Russet Burbank Potato. Plant Cell, Tiss. and Org. cult. 69: 197-200.

Xiao $Y$ and Kozai T (2004) Commercial application of a photoautotrophic micropropagation system using large vessels with forced ventilation: plantlet growth and production cost. Hort. Sci. 39(6): 1387-1391.

Zobayed S M A, Kubota C and Kozai T (1999) Development of a forced ventilation micropropagation system for large scale photoautotrophic culture and its utilization in sweet potato. In Vitro Cell Dev Bio. Plant 35: 350-355 